\title{
Silver-Catalyzed Hydrogenation of Ketones under Mild Conditions
}

\author{
Shengdong Wang,,$\stackrel{\text { a, }}{ }$ Haiyun Huang,,${ }^{\mathrm{a} \ddagger}$ Svetlana Tsareva, ${ }^{\mathrm{b}}$ Christian Bruneau, ${ }^{\mathrm{a}}$ and \\ Cédric Fischmeister ${ }^{a^{*}}$
}

\author{
${ }^{a}$ S. Wang, H. Huang, Dr. C. Bruneau, Dr. C. Fischmeister \\ Univ Rennes, CNRS, ISCR (Institut des Sciences Chimiques de Rennes) - UMR 6226 \\ F-35042 Rennes, France.E-mail: cedric.fischmeister@univ-rennes1.fr \\ ORCID C. Fischmeister 0000-0002-9490-8145 \\ ${ }^{\mathrm{b}}$ S. Tsareva, Univ Rennes, CNRS, ScanMat - UMS 2001, F-35000 Rennes, France. \\ These two authors contributed equally to this work.
}

Received: ((will be filled in by the editorial staff))

\begin{abstract}
Supporting information for this article is available on the WWW under http://dx.doi.org/10.1002/adsc.201\#\#\#\#\#\#.((Please delete if not appropriate))
\end{abstract}

\begin{abstract}
The silver-catalyzed hydrogenation of ketones using $\mathrm{H}_{2}$ as hydrogen source is reported. Silver nanoparticles are generated from simple silver (I) salts and operate at $25{ }^{\circ} \mathrm{C}$ under 20 bar of hydrogen pressure. Various aliphatic and aromatic ketones, including natural products were reduced into the corresponding alcohols in high yields.
\end{abstract}

\section{Introduction}

Reduction processes play a crucial role in numerous industrial processes and for this reason they have been a topic of continuous intense researches in academia and industry. This situation will very likely persist owing to the growing demand for biosourced compounds yet requiring reduction and hydrogenation protocols. ${ }^{[1]}$ Industrial hydrogenation processes are essentially employing heterogeneous catalysis excepted when highly selective transformations are necessary albeit a number of heterogeneous catalyst display this property. Metal nanoparticles are at the frontier between homogeneous and heterogeneous catalysis as they display in general high activity and selectivity and can be recycled. For these reasons, metal nanoparticles (NPs) have been attracting a strong interest over the past 20 years in catalysis. ${ }^{[2]}$ Among metal-NPs, silver-NPs (Ag-NPs) are receiving attention as an alternative to expensive metal-NPs based on gold, platinum or other noble transition metals. $^{[3]}$ The efficient and selective reduction of aldehydes was extensively studied by Claus since the mid-nineties using Ag-NPs supported on $\mathrm{SiO}_{2}$ or $\mathrm{TiO}_{2}{ }^{[4]}$ Ag-NPs have also been reported for the hydrogenation of nitro-aromatics into aniline derivatives $^{[5]}$ and for the selective hydrogenation of amides into alcohols and amines. ${ }^{[6]}$ The hydrogenation of keto-derivatives with Ag-NPs turns to be more difficult and only a few recent results are published. As an illustration, we could mention that during his investigations on the scope of the Ag-NPs hydrogenation of nitroaromatics, Shimizu reported
This silver catalyst allows for the selective hydrogenation of ketones in the presence of other functional groups.

Keywords: Catalysis; Hydrogenation; Ketones; Nanoparticles; Silver

that an acetyl group was not hydrogenated by $\mathrm{Ag}$ NPs supported on alumina when the reaction was conducted at $160{ }^{\circ} \mathrm{C}$ under 30 bar of hydrogen pressure. ${ }^{[5]}$ In another example, Moores and $\mathrm{L}_{1}$ reported the hydrogenation of two benzylic ketones using magnetic $\mathrm{Ag}-\mathrm{F}_{3} \mathrm{O}_{4}$ nanoparticles supported o. carboxymethyl cellulose. The corresponding alcohols were obtained in moderate to high yield at $100{ }^{\circ} \mathrm{C}$ and 40 bar of hydrogen pressure in water. ${ }^{[7]}$ In 2009 , De Vos reported polymer stabilized Ag-NPs that reduced a number of unsaturated ketones with moderate to high selectivity at $60{ }^{\circ} \mathrm{C}$ and 40 bar of hydrogen pressure. ${ }^{[8]}$ More recently, Moores described the use of plasmonic silver nanocubes for the hydrogenation of ketones and aldehydes. Four ketones were hydrogenated at $80{ }^{\circ} \mathrm{C}$ and 1 bar of hydrogen pressure under irradiation at $450 \mathrm{~nm} .{ }^{\text {[9] }}$

In our ongoing efforts to produce the biosourced $\gamma$ valerolactone by reduction of levulinic acid with iridium complexes, ${ }^{[10]}$ we became interested in using less expensive metals for hydrogenation reactions. Initially inspired by the work of $\mathrm{Li}^{[11]}$ on the homogeneous hydrogenation of aldehydes, we focused our attention on the silver-catalyzed hydrogenation of ketones (Scheme 1). 
(a) C.-J. Li, 2013

$$
\underset{\mathrm{R}}{\stackrel{\mathrm{DIPEA}^{1}(20 \mathrm{~mol} \%), \mathrm{H}_{2}=40 \mathrm{bar}}{\mathrm{AgPF}_{6}(5 \mathrm{~mol} \%), \mathrm{XPhos}(7.5 \mathrm{~mol} \%)}} \mathrm{P}_{\mathrm{C}, \mathrm{H}_{2} \mathrm{O}}
$$

(b) This work

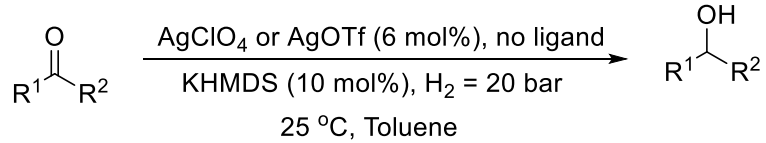

Scheme 1. Silver-catalyzed hydrogenation of carbonyl derivatives

\section{Results and Discussion}

Acetophenone was initially selected as a model substrate. Several experimental parameters were screened and optimized. As depicted in Table 1, we first investigated the hydrogenation catalyzed by silver triflate at $25{ }^{\circ} \mathrm{C}$ with KHMDS as the base in apolar solvents, in which very good yields were obtained (Table 1, entries1-2). More polar ether solvent resulted in lower yields of 1-phenylethanol (Table 1, entries 3-5). Following this first screening, various silver salts were evaluated emphasizing the superiority of silver perchlorate (Table 1, entries 311). Further optimization reactions were then pursued with this catalyst. Interestingly, it was possible to decrease the amount of base to $10 \mathrm{~mol} \%$ but decreasing the catalyst loading or the hydrogen pressure led to lower yields of alcohol (Table 1, entries 16-17). Various bases were also evaluated (Table 1, entries 18-24) but none of them led to the results obtained with KHMDS. In fact, all those bases led to very poor results indicating a very peculiar role of KHMDS. Finally, experiments conducted in the absence of $\mathrm{AgClO}_{4}$ or KHMDS were found totally ineffective hence demonstrating the necessity of both components (Table 1, entries 25-26).

With these optimized conditions in hand, we performed the hydrogenation of a number of commercially available ketones to highlight the efficacy of the catalytic system. Selected aromatic and aliphatic ketones featuring various steric and electronic demands were thus subjected to the catalytic system at $25{ }^{\circ} \mathrm{C}$. However, in some examples it was necessary to warm the reactions to $60{ }^{\circ} \mathrm{C}$ in order to reach good yields. In several cases, full conversions were obtained leading to very clean reaction mixtures. In those cases, the products were isolated by a simple filtration on a short plug of silica. As shown in Table 2, sterically hindered ketones and both electron-withdrawing as well as electrondonating substituted aromatic ketones were hydrogenated in high yields (entries 1-14). Under the standard reaction conditions, $p$-acetyl-acetophenone 10 was partially hydrogenated furnishing the monoreduced ketone $\mathbf{2 0}$ in $92 \%$ yield (Table 2, entry 15).
Table 1. Ag-catalyzed hydrogenation of acetophenone ${ }^{[a]}$<smiles>CC(=O)c1ccccc1</smiles>

1a
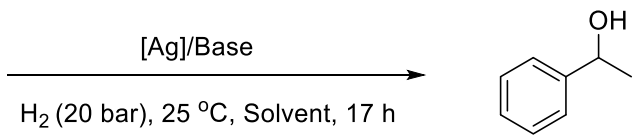

\begin{tabular}{|c|c|c|c|c|}
\hline Entry & Catalyst & Base & Solvent & Yield $(\%)^{b}$ \\
\hline 1 & AgOTf & KHMDS & Pentane & 85 \\
\hline 2 & AgOTf & KHMDS & Toluene & 92 \\
\hline 3 & AgOTf & KHMDS & THF & 73 \\
\hline 4 & AgOTf & KHMDS & CPME & 62 \\
\hline 5 & AgOTf & KHMDS & $\begin{array}{l}1,4- \\
\text { Dioxane }\end{array}$ & 82 \\
\hline 6 & $\mathrm{AgCl}$ & KHMDS & Toluene & $<5$ \\
\hline 7 & $\mathrm{Ag}_{2} \mathrm{O}$ & KHMDS & Toluene & 10 \\
\hline 8 & $\mathrm{Ag}_{2} \mathrm{CO}_{3}$ & KHMDS & Toluene & 33 \\
\hline 9 & $\mathrm{AgPF}_{6}$ & KHMDS & Toluene & 83 \\
\hline 10 & $\mathrm{AgSbF}_{6}$ & KHMDS & Toluene & 89 \\
\hline 11 & $\mathrm{AgClO}_{4}$ & KHMDS & Toluene & $99^{e}$ \\
\hline 14 & $\mathrm{AgClO}_{4}$ & $\begin{array}{l}\text { KHMDS } \\
(10)\end{array}$ & Toluene & $99^{e}(99)^{f}$ \\
\hline 15 & $\mathrm{AgClO}_{4}$ & KHMDS (5) & Toluene & 90 \\
\hline 16 & $\mathrm{AgClO}_{4}{ }^{c}$ & $\begin{array}{l}\text { KHMDS } \\
\text { (10) }\end{array}$ & Toluene & 78 \\
\hline $17^{d}$ & $\mathrm{AgClO}_{4}$ & $\begin{array}{l}\text { KHMDS } \\
(10)\end{array}$ & Toluene & 52 \\
\hline 18 & $\mathrm{AgClO}_{4}$ & $\operatorname{LDA}(10)$ & Toluene & $<5$ \\
\hline 19 & $\mathrm{AgClO}_{4}$ & $\mathrm{NaOEt}(10)$ & Toluene & $<5$ \\
\hline 20 & $\mathrm{AgClO}_{4}$ & $\mathrm{Cs}_{2} \mathrm{CO}_{3}(10)$ & Toluene & $<5$ \\
\hline 21 & $\mathrm{AgClO}_{4}$ & $\begin{array}{l}\text { HCOONa } \\
\text { (10) }\end{array}$ & Toluene & $<5$ \\
\hline 22 & $\mathrm{AgClO}_{4}$ & $t \mathrm{BuOK}(10)$ & Toluene & 11 \\
\hline 23 & $\mathrm{AgClO}_{4}$ & $\mathrm{NaOH}(10)$ & Toluene & $<5$ \\
\hline 24 & $\mathrm{AgClO}_{4}$ & $\mathrm{~K}_{2} \mathrm{CO}_{3}(10)$ & Toluene & $<5$ \\
\hline 25 & - & KHMDS(5) & Toluene & 0 \\
\hline 26 & $\mathrm{AgClO}_{4}$ & - & Toluene & 0 \\
\hline
\end{tabular}

2 a
$\mathrm{H}_{2}\left(20\right.$ bar), $25^{\circ} \mathrm{C}$, Solvent, $17 \mathrm{~h}$

[a] Reaction conditions: acetophenone $(0.5 \mathrm{mmol}),[\mathrm{Ag}](6$ mol\%), Base (20 mol\% unless other value mentioned), $\mathrm{H}_{2}=20$ bar, Solvent $(2 \mathrm{~mL}), 25^{\circ} \mathrm{C}$ (oil bath), 17 h. ${ }^{[b]}$ Determined by ${ }^{1}$ HNMR. [c] 3 mol\%. [d] $\mathrm{H}_{2}=10$ bar. [e] NMR signals of acetophenone not detected by ${ }^{1} \mathrm{H}$ NMR. ${ }^{[\mathrm{f}]}$ isolated yield.

Of note, the fully hydrogenated product $\mathbf{2 0}$ ' could be obtained upon heating the reaction at $60^{\circ} \mathrm{C}$. Aliphatic ketones including the naturally occurring and sterically hindered camphor $\mathbf{1 r}$ were also hydrogenated in very good yields (Table 2, entries 16-18). Similarly, heterocyclic keto-compounds were reduced to the corresponding alcohols in high yields. In the case of 3-acetyl-1-methylpyrrole $\mathbf{1 u}$ and 2benzofuranyl methyl ketone $\mathbf{1 v}$, a slight heating at $60{ }^{\circ} \mathrm{C}$ was necessary to ensure good yields (Table 2 , entries 21-22). Finally, the chemoselectivity of the catalytic system was evaluated using a series of bifunctional keto-derivatives. Aldehydes were also introduced in this study in order to demonstrate the applicability of the catalytic system to the hydrogenation of aldehydes. In all cases, the selective reduction of the ketone or aldehyde functional group took place delivering the alcohols in good to high yields (Table 2, entries 23-26). One limitation was 
nevertheless observed with the challenging benzylidene acetone 1aa which delivered a mixture of alcohol 2aa and ketone 2aa'in a 30/70 ratio. ${ }^{[11]}$ Finally, in order to highlight the general applicability of this catalytic system and draw some lines for further developments, we have attempted and succeeded with the selective hydrogenation of benzonitrile1ab. If the reaction of nitrile was not observed at room temperature (Table 2, entry 24), raising the temperature to $80{ }^{\circ} \mathrm{C}$ and the hydrogen pressure to 40 bar enabled the reduction of benzonitrile 1ab into benzylamine 2ab in 83\% isolated yield (Table 2, entry 28).

Table 2. Silver-catalyzed hydrogenation of ketones: Substrate scope ${ }^{[\mathrm{a}]}$

(Isolated yield

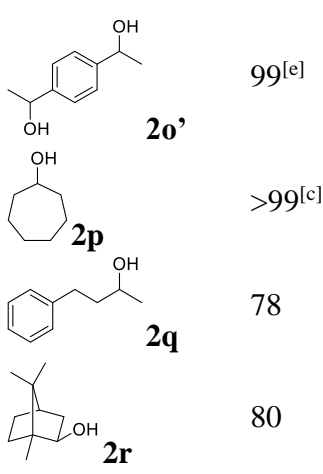

19<smiles>O=C1CCCCC1</smiles>

17

18

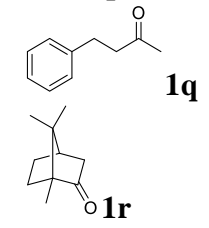

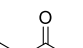<smiles>[AlH2]Cc1ccc[nH]1</smiles>

20<smiles>O=C(c1ccccc1)c1ccc(I)cc1</smiles>

21<smiles></smiles>

22

23<smiles>O=C([AlH2])c1cc2ccccc2o1</smiles><smiles></smiles>

24<smiles>CC(=O)c1ccc([N+](=O)[O-])cc1</smiles><smiles>[14CH3]CC(O)c1ccccn1</smiles>

79

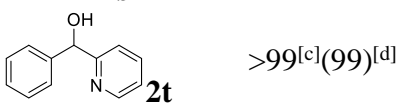<smiles>CCC(C)C(C)O</smiles>

$88^{[\mathrm{e}]}$

$97^{[\mathrm{e}]}$

$88(99)^{[\mathrm{d}]}$

93

25

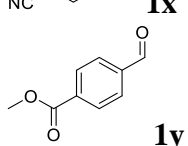

26
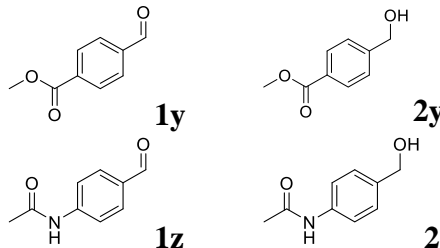

$>99^{[\mathrm{c}]}(83)^{[\mathrm{d}]}$
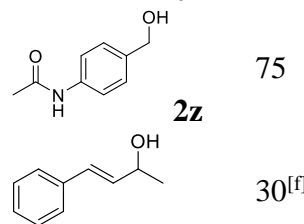

27

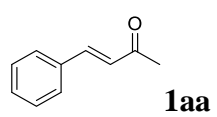

2aa<smiles>CC(=O)CCc1ccccc1</smiles>

$70^{[\mathrm{f}]}$

2aa'<smiles>N#Cc1ccccc1</smiles>
1ab

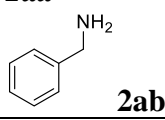

83

[a] Reaction conditions: substrate $(0.5 \mathrm{mmol}), \mathrm{AgClO}_{4}$ (6 mol\%), KHMDS (10 mol\%), $\mathrm{H}_{2}=20$ bar, toluene $(2 \mathrm{~mL}), 25^{\circ} \mathrm{C}$ (oil bath), $17 \mathrm{~h}$. ${ }^{[\mathrm{b}]}$ isolated by coloumn ${ }^{[\mathrm{c}]}$ Product isolated by simple filtration on a silica plug. ${ }^{[\mathrm{d}]}$ Results in parenthesis obtained with AgOTf as catalyst, 24 h. ${ }^{e} 60{ }^{\circ} \mathrm{C}$ (oil bath). ${ }^{[\mathrm{f}] 1} \mathrm{H}$ NMR ratio. ${ }^{[\mathrm{g}]} \mathrm{AgOTf}(6 \mathrm{~mol} \%)$, KHMDS (20 mol\%), $80{ }^{\circ} \mathrm{C}, 17$ $\mathrm{h}$

If the use of silver perchlorate in catalytic amounts and small scale syntheses should not present important safety issues, the situation may be different on larger scale syntheses. Considering this potential hazard, we have duplicated some reactions with silver triflate. These reactions performed over an extended reaction time of $24 \mathrm{~h}$ led in general to similarly good yields (Table 2 , entries $4,5,7,13,20,23,25$ ). It is worth mentioning that the repeatability and reproducibility of the reaction was checked with several substrates. 
Following our investigations on the efficiency and scope of the reaction, we turned our attention to the nature of the catalyst. Although we did not employ any nanoparticle stabilizer or support, the involvement of Ag-NPs was considered seeing the heterogeneous nature of the reaction media at the end of the catalytic transformations. As explained in a review by Finke, ${ }^{[12]}$ there is not a single test leading to unambiguous distinction between homogeneous or metal-NPs catalysis. Hence, we have conducted a series of experiments in order to identify the nature of the catalyst. We have first considered the mercury poisoning test with both silver precursors in the reduction of $1 \mathrm{a}(\mathrm{Hg} / \mathrm{Ag}=300)$. However, due to experimental constraint (high pressure reactor), mercury was added at the onset of the reaction. In both cases we observed complete inhibition of the reaction. Next, the reusability of the catalyst was evaluated. Two different procedures were used and in both cases very good yields were obtained in a second run (see SI for details). The kinetic profile of the reaction was also investigated with AgOTf precursor. It was found that the reaction proceeded without induction period hence suggesting a homogeneous catalytic process or fast generation of Ag-NPs (see SI for details).

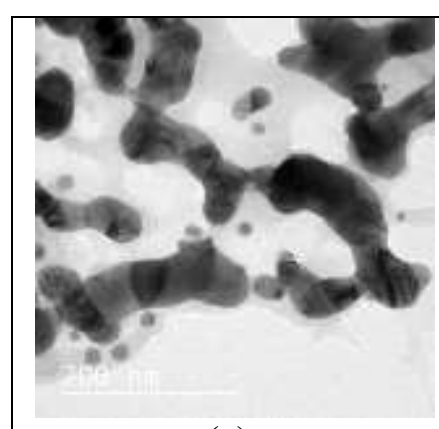

(a)



(c)

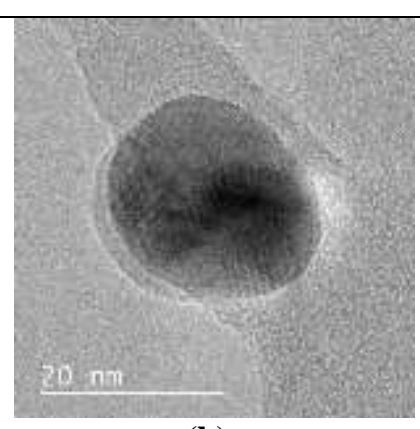

(b)

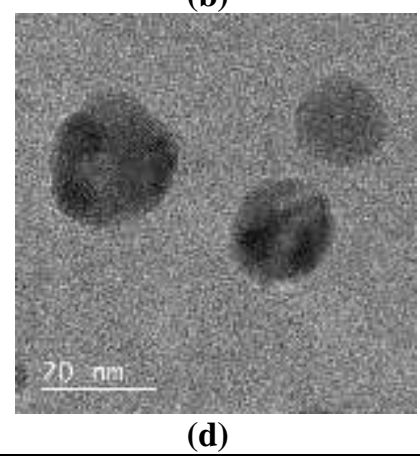

Figure 1: TEM images of reaction mixtures with AgOTf as precursor; (a) and (b) after 15 minutes; (c) and (d) after $17 \mathrm{~h}$.

Finally, the reaction mixture was analyzed by Transmission Electron Microscopy (Figure 1). Two reactions were conducted with AgOTf precursors and stopped after $15 \mathrm{~min}$ and $17 \mathrm{~h}$. After decantation, an aliquot of the supernatant liquid of each reaction was taken and deposited onto a TEM copper grid. As depicted in Figure 1, TEM images revealed the formation of nanoparticles with disperse size distribution due to agglomeration. In all cases EDS analyses on several particles for each samples evidenced the formation of silver nanoparticles (see SI for details). The observation of Ag-NPs after only 15 minutes of reaction is in agreement with fast initiation observed in kinetic studies. The unambiguous formation of nanoparticles raises the issue of stabilizers in general necessary to prevent extensive agregation of nanoparticles. Considering that hydrogenation reactions promoted by metalnanoparticles do not require a base, ${ }^{[5,7-9,13]}$ we believe that the bulky potassium hexamethyldisilazide initially introduced as a base necessary for hydrogen activation in an homogeneous catalytic reaction may play the role of stabilizing agent via electrostatic and/or electrosteric effects which are known processes for metal nanoparticle stabilization. ${ }^{[14]}$

\section{Conclusion}

In summary, the unprecedented hydrogenation of ketones with a silver catalyst is reported. These in situ generated silver nanoparticles operate at $25^{\circ} \mathrm{C}$ and low hydrogen pressure. High efficacy and selectivity have been achieved in a number of cases involving various ketones. These important characteristics make this process interesting for the synthesis of a broad range of chemicals. Further studies will be carried out to elucidate the noncommon formation of nanoparticles and to extend th applicability of these catalysts.

\section{Experimental Section}

General procedure for the catalytic hydrogenation of ketones: In an argon-filled glove box, a high pressure reactor was charged sequentially with base $(5-20 \mathrm{~mol} \%)$, silver salt $(6 \mathrm{~mol} \%)$, ketone $(0.5 \mathrm{mmol})$ and $2 \mathrm{~mL}$ of dry toluene. The reactor was then charged with $\mathrm{H}_{2}(20 \mathrm{bar})$ and stirred at the appropriate temperature for $17 \mathrm{~h}$. The reactor was carefully depressurized and the reaction mixture was filtrated through a short plug of silica. The solvent was evaporated and the crude product was analyzed by ${ }^{1} \mathrm{H}$ NMR. This crude product was then purified by flash column chromatography on silica gel using a mixture of heptane and ethyl acetate as the eluent.

\section{Acknowledgements}

The authors acknowledge the China Scholarship Council for a grant to SW. We also acknowledge M. Julien Hervochon for checking the reproducibility of the catalytic process.

\section{References}

[1] (a) P. J. Deuss, K. Barta, J. G. de Vries, Catal. Sci. Technol.2014, 4, 1174-1196 ; b) K. Barta, P. C. Ford, Acc. Chem. Res. 2014, 47, 1503 ; c) M. J. Climent, A. Corma, S. Iborra, Green Chem. 2014, 16, 516. 
[2] (a) S. Pedro, A. Corma, ACS Catal., 2015, 5, 71147121; (b) C.-J. Jia, F. Schüth, Phys. Chem. Chem. Phys. 2011, 13, 2457-248; (c) R.Cuenya, Thin Film Solids, 2010, 518, 3127-3150.

[3] (a) C. Wen, A. Yin, W.-L. Dai, Appl.Catal.B: Environ., 2014, 160-161, 730-741; (b) X.-Y. Dong, Z.-W. Gao, K.-F. Yang, W.-Q. Zhang, L.-W. Xu, Catal. Sci. Technol., 2015, 5, 2554-2574.

[4] (a) P. Claus, H. Hofmeister, J. Phys. Chem. B, 1999, 103, 2766-2775; (b) W. Grünert, A. Brückner, H. Hofmeister, P. Claus, J. Phys. Chem. B, 2004, 108, 5709-5717. (c) M. Bron, D. Teschner, A. Knop-Gericke, B. Steinhauer, A. Scheybal, M. Hävecker, D. Wang, R. Födisch, D. Hönicke, A. Wootsch, R. Schlögl, P. Claus, J. Catal., 2005, 234, 37-47.

[5] (a) K.-i. Shimizu, Y. Miyamoto, A. Satsuma, J. Catal., 2010, 270, 86-94; (b) Y. Chen, C. Wang, H. Liu, J. Qiu, X. Bao, Chem. Commun., 2005, 5298-5300.

[6] Y. Xie, P. Hu, T. Bendykov, D. Milstein, Catal. Sci. Technol. 2018, 8, 2784-2788

[7] A. You Li, M. Kaushik, C. J. Li, A. Moores, ACS Sust. Chem. Eng., 2016, 4, 965-973.

[8] P. G. N. Mertens, P. Vandezande, X. Ye, H. Poelman, I. F. J. Vankelekom, D. E. De Vos, Appl. Catal. A: Gen., 2009, 355, 176-183.

[9] M. J. Landry, A. Gellé, B. Y. Meng, C. J. Barret, A. Moores, ACS Catal., 2017, 7, 6128-6133.

[10] (a) S. Wang, V. Dorcet, T. Roisnel, C. Bruneau, C. Fischmeister, Organometallics, 2017, 36, 708-713; b) S.
Wang, H. Huang, V. Dorcet, T. Roisnel, C. Bruneau, C. Fischmeister, Organometallics, 2017, 36, 3152-3162; c) S. Wang, H. Huang, C. Bruneau, C. Fischmeister, ChemSusChem, 2017, 10, 4150-4154.

[11] Several recent examples highlight the difficulty to perform the selective hydrogenation or transfer hydrogenation of benzylideneacetone : (a) A. BruneauVoisine, D. Wang, V. Dorcet, T. Roisnel, C. Darcel, J.-B. Sortais, Org. Lett. 2017, 19, 3656-3659 ; (b) D. Wei, A. Bruneau-Voisine, T. Chauvin, V. Dorcet, T. Roisnel, D. M. Valyaev, N. Lugan, J.-B. Sortais, Adv. Synth. Catal. 2018, 360, 676-681; (c) D. Wei, T. Roisnel, C. Darcel, E. Clot. J.-B. Sortais, ChemCatChem, 2017, 9, 80-83; (d) R. Xu, S. Chakraborty, S. M. Bellows, H. Yuan, T. R. Cundari, W. D. Jones, ACS Catal. 2016, 6, 2127-2135, (e) K. L. Luska, A. Bordet, S. Tricard, I. Sinev, W. Grünert, B. Chaudret, W. Leitner, ACS Catal. 2016, 6 , 3719-3726; (f) K. Farrell, H. Müller-Bunz, M. Albrech,, Organometallics, 2015, 34, 5723-5733; (g) G. Zhang, S. K. Hanson, Chem. Commun., 2013, 49, 10151.

[12] J. A. Widegren, R. G. Finke, J. Mol. Catal. A: Chem. 2003, 198, 317-341.

[13] (a) J. Llop Castelbou, E. Bresó-Femenia, P. Blondeau, B. Chaudret, S. Castillón, C. Claver, C. Godard, ChemCatChem, 2014, 6, 3160-3168; L. Yang, C. Cheng, L. Xia, H. Liu, RSC Advances, 2016, 6, 31871-31875;

[14] (a) A. Roucoux, Top. Organomet. Chem. 2005, 16, 261-279; (b) C. Janiak, Z Naturforschung B, 2014, 68 . 1059-1089; 
Adv. Synth. Catal. Year, Volume, Page - Page

Shengdong Wang,,${ }^{a, \downarrow}$ Haiyun Huang,${ }^{a,+}$ Svetlana

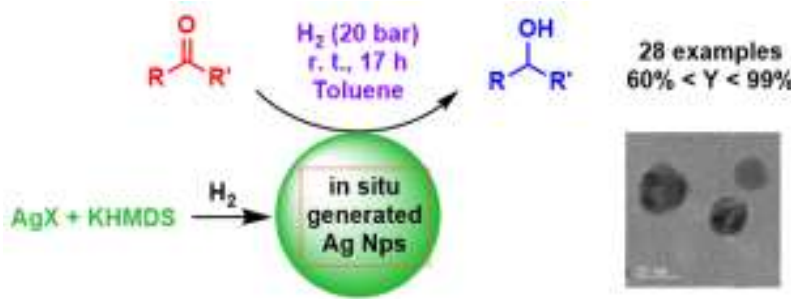

Tsareva, ${ }^{\mathrm{b}}$ Christian Bruneau, ${ }^{\mathrm{a}}$ and Cédric

Fischmeister $^{\mathrm{a}^{*}}$ 